\title{
Autocorrelated Order-Imbalance and Price Momentum in the Stock Market
}

\author{
Rahul Ravi ${ }^{1} \&$ Yuqing Sha ${ }^{1}$ \\ ${ }^{1}$ John Molson School of Business, Concordia University, Montreal, Canada \\ Correspondence: Rahul Ravi, John Molson School of Business, Concordia University, 1455 de Maisonneuve \\ Blvd. W. Montreal, Quebec H3G 1M8, Canada. Tel: 514-848-2424 ext. 2107. E-mail: rravi@jmsb.concordia.ca
}

Received: July 9, 2014

Accepted: July 24, 2014

Online Published: September 25, 2014

doi:10.5539/ijef.v6n10p39

URL: http://dx.doi.org/10.5539/ijef.v6n10p39

\begin{abstract}
This paper tracks the performance of order-imbalance based, momentum type trading strategy in the stock market. Buying previous day's heavily bought stocks and selling the heavily sold stocks earns statistically significant positive return. However, the magnitude of these returns has been steadily declining post 1998 . Known asset pricing factors do not explain these returns. Investor sentiment is able to explain at least some of these returns, supporting the notion that behavioral factors influence asset returns at least in the short run. Our results are robust to the calculation of returns using midpoints of quoted bid-ask prices, suggesting that microstructure biases are not driving our results.
\end{abstract}

Keywords: autocorrelated order-imbalance, price momentum

\section{Introduction}

This study exploits a long time series of transaction level data from the TAQ database to explore the existence of autocorrelated order-imbalance driven short-term momentum in daily stock prices. Our analysis is based on approximately 38 billion pairs of matched trades and quotes, spreading across all stocks in the CRSP database and spanning across eighteen years (January 1993 to December 2010). This study identifies the portfolio of most heavily bought stocks in the market on a given day and the portfolio of most heavily sold stocks in the market. It looks for persistence in buying and selling pressures for these portfolios the following day, and explores the resulting short-term momentum in prices.

This study is closely related to Chordia and Subrahmanyam (2004). They find evidence of positive autocorrelation in daily order-imbalance. They also find that lagged imbalance is positively related to daily stock returns and negatively related to monthly returns. They present their findings as evidence in support of short term over reaction and subsequent correction. We build on their finding in at least three ways. First, we expand the period of investigation to span across a longer time horizon, which includes periods of increased day trading and prevalence of various high frequency trading strategies. These strategies are specifically designed to identify and trade away temporary market inefficiencies. Arguably this should include known behavioral biases. Second, we develop a Jegadeesh and Titman (1993) type momentum trading strategy based on daily trading imbalances and track its performance through time (Note 1). Our choice of time period allows us to track the strategy through periods of rising market bubble, and its subsequent crash, the post bubble lull period and the financial market crash of 2008. Third, we present some evidence, hinting at the possibility of the existence of a systematic component in imbalance-based momentum return.

This study examines a very short horizon relative strength type strategy (one day holding period), which may be classified (in terms of the style) as a variant of the momentum trading strategy. We examine a buy and hold strategy, which requires the investor to buy stocks with high buy pressure (stocks with highest $10 \%$ buyer initiated fractional trading volume: BUY portfolio) on the previous trading day, and simultaneously sell stocks with high sell pressure (stocks with highest $10 \%$ seller initiated fractional trading volume: SELL portfolio) on the previous trading day. The investor takes position at market open and exits the market with zero position at market close. The trading strategy is based on the conjectures that the dominant buy/sell pressures experienced by a given stocks on the previous day are likely to be persistent through the next day.

Persistence in buy or sell pressure can be driven by various behavioral or non-behavioral factors. According to 
the strategic trading view, informed traders' attempt to hide their trades can potentially give rise to persistence in order-imbalance. According to Chordia \& Subrahmanyam (2004), these traders are inclined to split their orders over time to minimize the price impact of trades, thus causing positive autocorrelation in order imbalances. In turn, this autocorrelation causes correlation in price pressures, which potentially gives, rise to a positive autocorrelation in returns. From a largely uninformed perspective, Kumar and Lee (2006) find that when one group of retail investor buys (sells) stocks, another group of retail investors also buys (sells) stocks. This correlated trading causes persistence in volume of buyer-initiated trades or volume of seller-initiated trades.

From the sentiment based trading perspective, uninformed traders are likely to be swayed by prevailing mood in the market. When they believe the market is bullish on a given stock, they are likely to continue buying that stock, thus driving its prices up. In contrast, when the popular outlook is perceived to be pessimistic about a given stock, these investors will sell that stock thus driving its prices down. De Long, Shleifer, Summers, and Waldmann (1990) argue that when noise traders are pessimistic about an asset, they would drive down the asset's prices and in the near future, they might become even more pessimistic and drive down the prices further. Conversely, when investors are optimistic, they might buy stocks and drive asset prices up. Lee, Jiang and Indro (2002) argue that bullish (bearish) shifts in sentiment lead to higher (lower) future excess returns. They find that noise traders increase their holdings of an asset when their sentiment becomes more bullish and conversely sell more stocks when they believe the market is bearish. This "hold-more" effect is likely to cause a short-term positive autocorrelation in stock returns.

We find that in each of the eighteen years in the sample, the strategy earns positive returns ranging from $18.22 \%$ in 2007 to $119.11 \%$ in 1996. Moreover, controlling for market, size, book to market ratio, and momentum factors does not subsume these returns. The inability of the momentum factor to explain the results might suggest the existence of a driver different from the ones identified in the established JTM literature.

The issue of bid-ask bounce (first identified by Blume and Stambaugh, 1993) holds a particular relevance for our study. High imbalance on a given day would suggest a preponderance of trades at the ask (for the BUY portfolio) or at the bid (for the SELL portfolio). This would potentially contaminate any attempt to predict the following day return using trade prices. We attempt to resolve this issue using a set of returns calculated from the bid-ask midpoints. Results obtained from the quote mid-point based returns are virtually identical to those obtained from the trade price based returns.

The average daily return from the BUY-SELL position across the complete sample period is about 28 basis points. However, there is considerable variation across years. The strategy earns about 46 basis points per day during 1993 through 1998. However, It starts to decline steeply from 1999 through 2007. This decline may be possibly due to increased level of algorithmic trading in the market. These trading strategies are designed to capture very short-term inefficiencies prevailing in the market (Note 2). Applying a moderate 15 basis point transaction cost would suggest that although the returns from the imbalance based trading strategy continues to be statistically significant, it ceases to be economically significant post 2004 . However, with the emergence of cheaper trading venues, such as the dark pools, the statistically significant numbers might still be economically significant. If so, the continued existence of these positive returns poses a challenge to the notion of the weak form of market efficiency, albeit less serious of a challenge than it was pre 1999.

The remainder of this paper is organized as follows: Section 1 describes the data and summary statistics and presents our test methodology. Section 2 discusses our empirical results; section 3 explores the possibility of the BUY-minus-SELL factor being priced in short horizon asset returns, and Section 4 concludes our paper.

\section{Data and Methodology}

\subsection{Data}

The primary data for our study consist of the intraday trades and quotes from TAQ. Our sample period spans from January 1st 1993 to December 31st 2010 (for a total of 18 years). This span includes all phases of the market cycle ranging from the booming technology bubble in the mid to late 90s, its crash in 2000 and then the recessionary years post 2006. Our sample consists of the entire population of stocks contained in CRSP and TAQ databases. We start our analysis with a sample size of 34,793,186 stock days (spread across 18 years). Since our trading strategy involves fractional buyer and seller-initiated trades, illiquid stocks could bias the results. This issue is avoided by deleting all stocks below the lowest 20 percentile (by trading volume) in each trading year. The final sample consists of 22,475,317 stock days of data. The sample distribution by year is presented in Table 1. 
Table 1. Sample description

\begin{tabular}{|c|c|c|c|c|c|}
\hline year & \# of stocks & firm days & Number of trades & Market capitalization & Trading volume \\
\hline 1993 & 7892 & $1,181,370$ & $78,589,384$ & 583,321 & 246,797 \\
\hline 1994 & 8471 & $1,281,050$ & $83,697,192$ & 615,488 & 189,460 \\
\hline 1995 & 8886 & $1,364,282$ & $111,929,561$ & 589,924 & 219,202 \\
\hline 1996 & 9495 & $1,481,532$ & $146,581,934$ & 756,729 & 306,880 \\
\hline 1997 & 9759 & $1,561,355$ & $192,878,907$ & 875,534 & 260,735 \\
\hline 1998 & 9634 & $1,510,495$ & $269,244,475$ & $1,170,438$ & 249,968 \\
\hline 1999 & 9289 & $1,390,991$ & $464,255,230$ & $1,507,089$ & 640,073 \\
\hline 2000 & 8954 & $1,317,221$ & $787,857,366$ & $2,002,587$ & 668,384 \\
\hline 2001 & 8252 & $1,259,259$ & $800,526,157$ & $1,870,884$ & 525,419 \\
\hline 2002 & 7627 & $1,244,234$ & $908,860,888$ & $1,861,941$ & 515,113 \\
\hline 2003 & 7158 & $1,148,429$ & $1,123,368,844$ & $1,588,919$ & 491,743 \\
\hline 2004 & 7035 & $1,146,849$ & $1,480,623,113$ & $2,131,592$ & 629,972 \\
\hline 2005 & 7112 & $1,144,324$ & $1,824,460,442$ & $2,339,777$ & 790,712 \\
\hline 2006 & 7176 & $1,111,171$ & $2,502,699,322$ & $2,555,054$ & 880,572 \\
\hline 2007 & 7437 & $1,122,263$ & $4,425,067,834$ & $2,727,543$ & $1,048,713$ \\
\hline 2008 & 7176 & $1,127,460$ & $7,861,167,695$ & $2,886,805$ & 884,124 \\
\hline 2009 & 6876 & $1,035,774$ & $7,253,222,578$ & $1,884,208$ & 997,420 \\
\hline 2010 & 6831 & $1,047,258$ & $6,912,360,447$ & $2,468,316$ & $1,151,182$ \\
\hline Total & 145,060 & $22,475,317$ & $37,227,391,369$ & & \\
\hline
\end{tabular}

Note. This table reports the total number of stocks, the total number of firm days, the total number of trades, the average market capitalization per stock per day and the average trading volume per stock per day in each year.

We get the opening prices, closing prices, numbers of shares outstanding, and returns for our sample from the CRSP database. Transaction level trade and quote data is from the TAQ database. Following Chordia, Roll, and Subrahmanyam (2001), several filters are employed to ensure the validity of the TAQ data (Note 3 ). The TAQ database does not eliminate auto-quotes (passive quotes by secondary market dealers), which may cause the quoted spread to be artificially inflated. Since no reliable method can exclude auto-quotes in TAQ, we follow Chordia, Roll, and Subrahmanyam $(2001,2002)$ in using only BBO (best bid or offer) eligible primary market quotes are (Note 4).

The daily Fama-French three factors and the momentum factor are from Professor Kenneth R. French's data library (Note 5). The monthly investor sentiment index comes from Baker and Wurgler (2007)'s paper, (the data is available from Jeffrey Wurgler's website at Stern, NYU) (Note 6). The treasury 10-year interest rates, treasury 3-month interest rates and the Moody's AAA corporate bond yields (used to calculate default spread and term spread) are from Wharton Research Data Services (WRDS) 'Federal Reserve Bank Reports' dataset.

\subsection{Methodology}

We follow the Lee and Ready (1991) procedure for merging trade and quote data and for classifying trades. Since the trade direction is inferred from the available information and not observed, some assignment error is inevitable. Hence, the resulting order-flow data is an estimate. Nevertheless, as shown by Lee and Radhakrishna (2000) and Odders-White (2000), the Lee and Ready (1991)'s algorithm is largely accurate; thus, inferences based on the estimated order-flow should be reliable (Note 7). After merging and signing, the rest of our analysis is based on 37,227,391,369 pairs of trades and quotes. The annual distribution is presented in Table I.

We count the total number of buyer-initiated trades and seller-initiated trades for each stock each day and then calculate the percentage of buyer-initiated trades as the total number of buyer-initiated trades divided by the total number of trades. Decile portfolios are constructed on the basis of the fractional buy volume (Note 8).

At the end of each trading day, we rank the sample stocks by the fraction of buyer-initiated trade in each stock on that day. Using this ranking, we split the sample into decile portfolios. Thus, a stock gets assigned to portfolio 1 on any given day if it ranks among the top $10 \%$ stocks in terms of fraction of buyer initiated trade in that stock on that day. Stocks ranking among the 81st to 90th percentile form portfolio 2 and those falling among the 71st to 80 th percentile form portfolio 3 . We classify the portfolio of stocks falling among 21 st to 30 th percentile buy stocks as portfolio 4 and those in 11 th to 20 th percentile as portfolio 5 . The lowest $10 \%$ of buy stocks are classified as portfolio 6 . In other words, a stock gets assigned to portfolio 6 if it ranks among the top $10 \%$ stocks 
in terms of fraction of seller initiated trade in that stock on that day. The construction of our portfolios is based on the hypothesis of persistence in buys and sells. Therefore we only focus on the stocks ranking among the top three and bottom three deciles.

\subsubsection{Autocorrelation in Stock Returns}

The first set of tests focus on the autocorrelation patterns in returns of the stocks constituting the six portfolios formed above. Intuitively, a positive autocorrelation in stock returns would suggest that its own past high return predicts its future high return and similarly negative past return predicts negative future returns. Extant literature attributes daily return autocorrelation to three main sources. First: spurious autocorrelation caused by the use of stale prices (SA), second: autocorrelation caused by bid-ask bounce (BA), and third: autocorrelation arising due to partial price adjustment (PA) (For example, market frictions such as price-limits impeding the unhindered response of prices to news). Often a fourth source in the form of time varying risk premia is also cited as a possible source of positive autocorrelation (RA). However, Anderson (2011) shows that the RA effect is sufficiently small and in the daily setting it can be safely ignored.

Atchison, Butler and Simonds (1987), Lo and MacKinlay (1990) find that SA explains a very small part of total autocorrelation in portfolio returns. In a more recent study Bernhardt and Davis (2008) find that the impact of SA on portfolio return autocorrelation is negligible. We use a very large sample in this study, ranging across eighteen years. Spurious correlation is unlikely to be the variable consistently driving our results across all days/years. Moreover, stale prices are the result of thin trading (or non-synchronicity in trading). Since we have removed the most illiquid stocks from our sample, our results are unlikely to be affected by SA. We ignore this effect in this study. We address the bid-ask bounce related autocorrelation (BA) concern by running our analysis separately using two types of returns: first, return calculated using transaction prices, and second: return calculated using bid-ask midpoint.

The intuition of our study is based on expectation of persistence in buying and selling pressure across stocks. Thus:

Hypothesis 1: On average the stocks across each of the six portfolios should display significant positive autocorrelation.

Hypothesis 2: The autocorrelation in daily returns should be strongest for portfolios 1 and 6 , and display monotonic decline from 1 to 3 and from 6 to 4 .

We estimate the autocorrelation of returns for each stock on each day by using a simple first-order autoregressive model (Note 9):

$$
\mathrm{R}_{\mathrm{t}, \mathrm{i}}=\alpha+\beta \mathrm{R}_{\mathrm{t}-1, \mathrm{i}}+\varepsilon_{\mathrm{t}}
$$

Where $R_{t, i}$ is stock i's return on day $t$ and $R_{t-1, i}$ is stock i's return on its previous day. Autocorrelation is measured by the coefficient $\beta$. We expect $\beta$ to be positive on average. The magnitude of $\beta$ is expected to be highest for stocks comprising portfolio 1 and 6 . The magnitude is expected to decline from portfolio 1 to 3 and also from portfolio 6 to 4 .

\subsubsection{BUY and SELL Portfolio Returns}

The second set of tests focuses on constructing the 6 portfolios based on differing buy and sell pressures and estimating their returns over 1 day holding period. We identify the six portfolios after market close on day (t-1). On the morning of day $(\mathrm{t})$, we take a long position in the buy dominant portfolio and simultaneous short position in the corresponding sell dominant portfolio. For example, long portfolio 1, short portfolio 6. And finally, we close our position at market close on day $(\mathrm{t})$. Thus, in terms of the 1-6 example, we sell our long position in portfolio 1 and close the short position in portfolio 6 . The portfolio return is calculated as the open to close return on day $(t)$. We have used equally weighted portfolio returns for this part of the analysis (Note 10). We repeat the buy-hold-sell strategy every day across our sample period.

Hypothesis 3: Portfolios 1, 2 and 3 are expected to yield positive returns, while portfolios 4, 5 and 6 are expected to earn negative returns.

Hypothesis 4: Since the buying pressure declines from portfolio 1 to portfolio 3 and the selling pressure declines from portfolio 6 to portfolio 4, we expect the portfolio returns to decrease from portfolio 1 to portfolio 3 , and we expect the absolute value of portfolio returns to decrease from portfolio 6 to portfolio 4 .

The robustness of the portfolio returns is tested by risk adjusting the returns using several factor model specifications. First, Capital Asset Pricing Model (CAPM) described in Sharpe (1964) and Litner (1965) is used with MKT (market) as a single source of adjustment. A second model includes the two Fama-French (1993) 
factors SMB (Size) and HML (Book-to-market). In order to differentiate the BUY and SELL returns from the more popular momentum returns, we add the MOM (momentum) factor (Carhart (1997) 4-factor model) and re-examine the returns of portfolio 1 through 6 (Note 11).

\subsubsection{Determinants of BUY minus SELL Portfolio Returns}

We construct the Buy minus Sell Portfolio by taking a long position in Portfolio 1 and a simultaneous short position in Portfolio 6. The difference between the returns of Portfolio 1 and Portfolio 6 gives us the Buy minus Sell (BMS) return. We identify the following set of variables that could potentially explain the BMS factor:

Default and term spreads (DS and TS respectively) are two standard macroeconomic variables used to predict market returns. DS is defined as the difference between the average yield of bonds rated BAA by Moody's and the average yield of bonds with a Moody's rating of AAA, and is included to capture the effect of default premiums. Fama and French (1988) show that default premiums track long-term business cycle conditions, and document the fact that this variable is higher during recessions and lower during expansions. TS is the difference between the average yield of Treasury bonds with more than 10 years to maturity and the average yield of T-bills that mature in three months. Fama and French (1988) show that this variable is closely related to short-term business cycles.

We also include three different measures of market sentiment. The variables are: (1) the percentage of stocks whose price decreased via-a-vis the previous trading day (PCT_down), (2) The natural logarithm of the volatility index VIX, which is used to measure market's expectation of stock market volatility in short term, (3) Baker and Wurgler's Investor sentiment index. Apart from these, we include market capitalization of the portfolio and the return on S\&P 500 index (Market proxy) in the regression specification. The specification used is:

\section{Empirical Results}

$$
B M S_{t}=\alpha+\beta_{1} C A P_{t}+\beta_{2} P C T \_d o w n_{t}+\beta_{3} \ln { }_{-} S P 500_{t}+\beta_{4} l n_{-} V I X_{t}+\beta_{5} D S_{t}+\beta_{6} T S_{t}+\beta_{7} S I_{t}+\varepsilon_{t}
$$

Table 1 presents some annual descriptive statistics of the sample used in this study. The number of stocks in each year is fairly uniform. There is a slight decline in 2009 and 2010. Similarly the number of daily stock data in each year (sum of all the trading days across all the stocks in the sample) is also fairly uniform. This number is less than (Number of trading days in the year)*(Number of stocks), because not all stocks survive in the sample for the entire year. Some stocks drop out because of delisting; however the majority of the data point losses may be attributed to illiquidity. On each trading day we drop $20 \%$ of the most illiquid stocks from the sample. Total market capitalization and the trading volume have increased through time.

Table 2. Panel A: summary statistics

\begin{tabular}{lllllll}
\hline year & P1 & P2 & P3 & P4 & P5 & P6 \\
\hline 1993 & $1,524,393$ & $2,820,703$ & $3,908,142$ & $2,536,372$ & $1,635,667$ & $1,023,626$ \\
1994 & $1,495,695$ & $2,901,284$ & $4,092,544$ & $2,338,646$ & $1,521,696$ & $1,025,810$ \\
1995 & $1,718,911$ & $3,454,296$ & $5,018,781$ & $2,879,761$ & $1,809,281$ & $1,124,418$ \\
1996 & $1,965,271$ & $4,126,630$ & $6,054,684$ & $3,350,161$ & $2,095,048$ & $1,254,366$ \\
1997 & $1,915,103$ & $4,669,096$ & $7,729,877$ & $4,118,604$ & $2,284,345$ & $1,325,057$ \\
1998 & $2,030,959$ & $5,928,527$ & $10,575,362$ & $4,208,049$ & $2,200,827$ & $1,143,328$ \\
1999 & $2,062,072$ & $7,949,646$ & $14,331,244$ & $5,786,366$ & $2,522,139$ & $1,063,294$ \\
2000 & $2,959,733$ & $12,093,751$ & $20,479,866$ & $8,033,718$ & $2,958,517$ & $1,097,862$ \\
2001 & $2,873,358$ & $10,960,566$ & $17,630,518$ & $7,302,318$ & $2,547,067$ & 899,213 \\
2002 & $2,777,025$ & $10,842,320$ & $17,401,798$ & $6,375,601$ & $2,162,369$ & 856,524 \\
2003 & $3,470,975$ & $10,997,262$ & $16,631,860$ & $9,228,414$ & $3,185,355$ & $1,173,811$ \\
2004 & $6,251,138$ & $15,637,598$ & $20,904,716$ & $12,865,198$ & $4,739,334$ & $1,849,104$ \\
2005 & $7,197,260$ & $18,268,667$ & $24,600,307$ & $16,960,997$ & $6,624,377$ & $2,196,867$ \\
2006 & $8,907,147$ & $21,966,109$ & $30,483,615$ & $24,449,741$ & $9,574,647$ & $3,503,209$ \\
2007 & $10,195,004$ & $25,826,981$ & $43,407,168$ & $26,832,309$ & $12,320,317$ & $4,632,299$ \\
2008 & $5,199,274$ & $18,827,157$ & $46,022,435$ & $26,801,094$ & $10,773,778$ & $2,907,741$ \\
2009 & $3,713,178$ & $14,225,741$ & $32,454,141$ & $26,279,197$ & $10,519,117$ & $3,158,865$ \\
2010 & $5,786,539$ & $17,855,788$ & $37,346,052$ & $32,781,873$ & $14,881,761$ & $4,928,453$ \\
\hline
\end{tabular}

Note. The above table reports the average portfolio market capitalizations in each year. Portfolio 1 contains $10 \%$ of stocks with the highest fraction of buyer-initiated trades and Portfolio 6 contains $10 \%$ of stocks with the highest fraction of seller-initiated trades. Portfolio 2 (5) contains stocks for which $80 \%$ to $90 \%$ of trades are buyer (seller)-initiated trades; Portfolio 3(4) contains stocks for which over $70 \%$ but less than $80 \%$ of trades are buyer (seller)-initiated trades. 
Table 2 presents the descriptive statistics (by year) for the six portfolios described in section 1.2. Portfolio 1 (P1) consists of the $10 \%$ most heavily bought stocks (in terms of fraction of buyer vs. seller initiated trades in the stock). P6 represents the $10 \%$ most heavily sold stocks in the sample. Panel A presents the average daily market capitalization of the portfolios in each year. Comparing these numbers with the sample market cap in Table I, Panel A of Table 2 suggests that our portfolios (heavily bought and heavily sold stocks) mostly consist of relatively larger stocks in the sample. The smaller stocks seem to fall in the $30^{\text {th }}$ to the $70^{\text {th }}$ percentile in terms of fraction of buyer vs. seller initiated trading. Once again, we do see the increase in market capitalization through time. It declines post 2007.

Table 2. Panel B: summary statistics

\begin{tabular}{ccccccc}
\hline Year & P1 & P2 & P3 & P4 & P5 & P6 \\
\hline 1993 & $89.69 \%$ & $75.62 \%$ & $66.07 \%$ & $33.58 \%$ & $23.90 \%$ & $9.89 \%$ \\
1994 & $89.28 \%$ & $74.78 \%$ & $65.14 \%$ & $32.50 \%$ & $22.81 \%$ & $9.27 \%$ \\
1995 & $89.30 \%$ & $74.85 \%$ & $65.32 \%$ & $34.17 \%$ & $24.48 \%$ & $10.15 \%$ \\
1996 & $88.65 \%$ & $73.77 \%$ & $64.40 \%$ & $34.73 \%$ & $25.21 \%$ & $10.54 \%$ \\
1997 & $87.80 \%$ & $72.94 \%$ & $64.04 \%$ & $35.67 \%$ & $26.47 \%$ & $11.56 \%$ \\
1998 & $86.65 \%$ & $71.53 \%$ & $62.97 \%$ & $35.44 \%$ & $26.18 \%$ & $11.32 \%$ \\
1999 & $86.07 \%$ & $70.44 \%$ & $62.01 \%$ & $36.03 \%$ & $26.76 \%$ & $11.51 \%$ \\
2000 & $84.63 \%$ & $68.88 \%$ & $60.99 \%$ & $37.67 \%$ & $28.76 \%$ & $12.72 \%$ \\
2001 & $83.99 \%$ & $69.03 \%$ & $61.87 \%$ & $39.87 \%$ & $31.42 \%$ & $14.93 \%$ \\
2002 & $82.38 \%$ & $67.82 \%$ & $61.42 \%$ & $40.75 \%$ & $32.53 \%$ & $16.02 \%$ \\
2003 & $80.82 \%$ & $67.24 \%$ & $61.43 \%$ & $43.26 \%$ & $36.23 \%$ & $20.13 \%$ \\
2004 & $78.07 \%$ & $65.25 \%$ & $60.25 \%$ & $44.25 \%$ & $38.25 \%$ & $22.40 \%$ \\
2005 & $76.21 \%$ & $63.89 \%$ & $59.20 \%$ & $44.23 \%$ & $38.57 \%$ & $23.54 \%$ \\
2006 & $74.60 \%$ & $62.84 \%$ & $58.48 \%$ & $44.79 \%$ & $39.67 \%$ & $25.36 \%$ \\
2007 & $71.10 \%$ & $59.80 \%$ & $56.05 \%$ & $44.50 \%$ & $39.90 \%$ & $26.45 \%$ \\
2008 & $69.60 \%$ & $57.29 \%$ & $53.79 \%$ & $44.40 \%$ & $39.94 \%$ & $25.68 \%$ \\
2009 & $70.36 \%$ & $58.20 \%$ & $54.47 \%$ & $44.89 \%$ & $40.74 \%$ & $27.61 \%$ \\
2010 & $69.49 \%$ & $58.61 \%$ & $54.91 \%$ & $44.94 \%$ & $41.00 \%$ & $29.50 \%$ \\
\hline
\end{tabular}

Note. This table reports the average breakpoints of deciles of percentage of buyer-initiated trades in each portfolio each year.

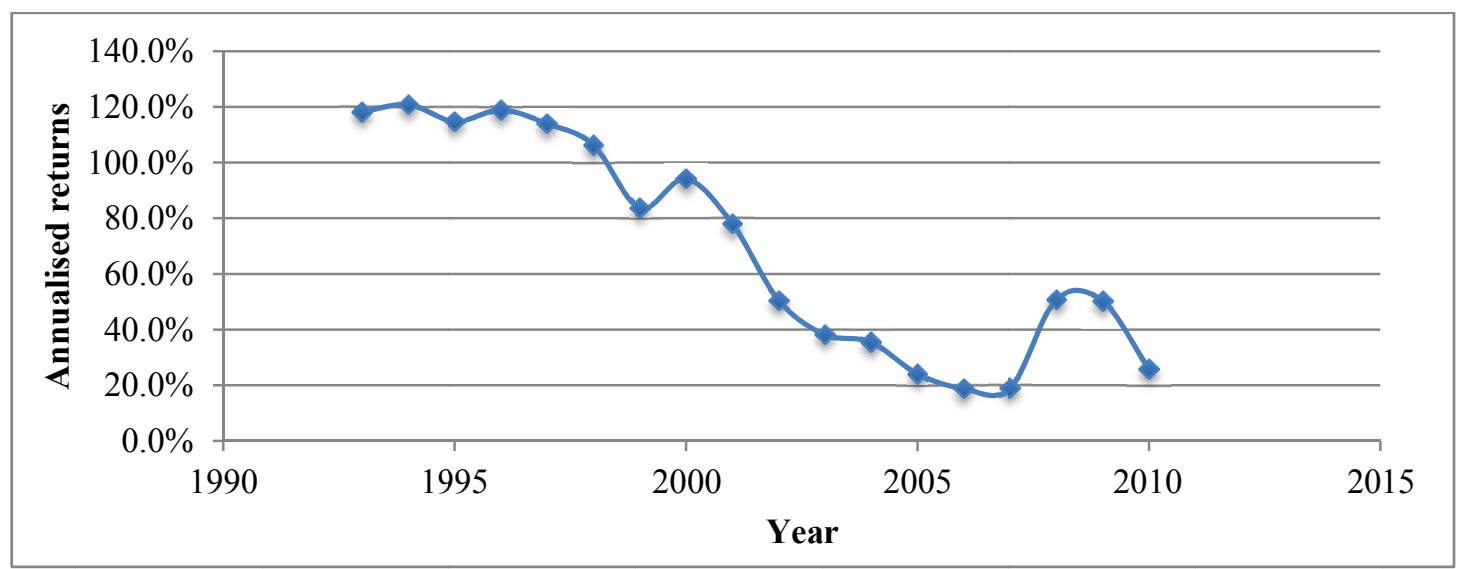

Figure 1. Annualized returns

Note. This figure presents the annualized portfolio return differences between the "buy" portfolio (Portfolio 1) and the "sell" portfolio (Portfolio 6) before adjusting for common risk factors.

Table 2, Panel B presents the portfolio breakpoints in terms of the fraction of buyer vs. seller initiated trades. For example, we see that in 1993, portfolio 1 consisted of stocks which had $89.69 \%$ of all trades initiated from the buy side, as opposed to portfolio 6 which had only $9.89 \%$ trades initiated by buyers $(91.11 \%$ trades initiated by the seller). Similarly Portfolio 2 consisted of stocks with 75.62 to $89.69 \%$ of the trades coming from the buy side. An interesting observation, which may be made from this table, is that through time, all the breakpoints seem to 
be gravitating towards $50 \%$. That is the $\mathrm{P} 1, \mathrm{P} 2$, and $\mathrm{P} 3$ breakpoints are declining while the $\mathrm{P} 4$, $\mathrm{P} 5$, and $\mathrm{P} 6$ breakpoints are increasing. While we do not explore what could be causing this trend, the numbers could have implications for the profitability of the strategy we are exploring in this paper. Hypothesis 4 would suggest that the declining buying pressure (through time) in portfolio 1 and the decreasing selling pressure in portfolio 6 should lead to declining strategy returns through time. We do observe a declining trend especially in portfolios 1 , 2 , and 3 (Table IV) as well as in the overall strategy (Figure 1).

\subsection{Autocorrelation in Stock Returns}

The average annual first order autocorrelation in stock returns is summarized in Table 2I. This table reports the autocorrelations based on open to close trade price (Note 12). The reported numbers are calculated as the average equation (1) $\beta$ coefficient. The coefficients are averaged across all stocks for each of the six portfolios, by year. Two main results are of interest here. First, autocorrelations are almost always positive. This supports our Hypothesis 1. To the extent that the reported autocorrelation is at a stock level (averaged within each portfolio classification), it is not entirely surprising to see several non-significant numbers (Note 13).

Table 3. The average coefficients of AR (1) model for six portfolios

\begin{tabular}{|c|c|c|c|c|c|c|}
\hline Year & $\mathrm{P} 1$ & $\mathrm{P} 2$ & $\mathrm{P} 3$ & $\mathrm{P} 4$ & P5 & P6 \\
\hline 1993 & $0.04 *$ & $0.064 * * *$ & $0.072 * * *$ & $0.033 * * *$ & $0.037 * * *$ & $0.044 * * *$ \\
\hline 1994 & 0.022 & $0.05 * * *$ & $0.048 * * *$ & $0.06 * * *$ & $0.067 * * *$ & 0.006 \\
\hline 1995 & $0.069 * * *$ & $0.072 * * *$ & $0.052 * *$ & 0.015 & $0.033^{*}$ & -0.057 \\
\hline 1996 & 0.041 & $0.059 * * *$ & $0.022 * *$ & $0.068 * * *$ & $0.047 * * *$ & 0.006 \\
\hline 1997 & $0.055 * * *$ & $0.023 * * *$ & $0.022 * *$ & $0.029 * *$ & $0.041 * * *$ & 0.015 \\
\hline 1998 & $0.077 * * *$ & $0.033 * *$ & $0.045^{* * *}$ & $0.052 * * *$ & $0.061 * * *$ & $0.037 * * *$ \\
\hline 1999 & $0.069 * * *$ & 0.023 & $0.044 * * *$ & $0.033 * * *$ & $0.044 * * *$ & 0.047 \\
\hline 2000 & $0.075^{* *}$ & $0.038 * * *$ & $0.05^{* * *}$ & $0.049 * * *$ & 0.036 & $0.07 * * *$ \\
\hline 2001 & $0.052 * * *$ & $0.047 * * *$ & $0.061 * * *$ & $0.057 * * *$ & $0.064 * * *$ & $0.051 * * *$ \\
\hline 2002 & $0.021 * *$ & 0.01 & 0.013 & $0.021 * * *$ & $0.031 * * *$ & -0.055 \\
\hline 2003 & $0.023 * *$ & $0.011^{*}$ & $0.015^{* *}$ & $0.023 * * *$ & 0.01 & $0.039 * * *$ \\
\hline 2004 & $0.048 * * *$ & $0.025 * *$ & $0.021 * *$ & $0.027 * * *$ & $0.057 * * *$ & $0.047 * * *$ \\
\hline 2005 & $0.018^{* *}$ & $0.015 * *$ & $0.019 * * *$ & $0.015^{*}$ & $0.022 * *$ & $0.05^{*}$ \\
\hline 2006 & $0.035^{* * *}$ & $0.014 * *$ & $0.02 * *$ & $0.036 * * *$ & 0.004 & $0.038 * * *$ \\
\hline 2007 & 0 & 0.009 & -0.008 & -0.01 & -0.012 & 0.009 \\
\hline 2008 & 0.151 & -0.027 & -0.009 & $0.022 * *$ & $0.027 * * *$ & $0.045^{*}$ \\
\hline 2009 & $0.035^{* * *}$ & -0.002 & 0.005 & 0.49 & $0.017 * *$ & $0.028 * * *$ \\
\hline 2010 & $0.037 * * *$ & 0.005 & 0.006 & $0.014 *$ & 0.007 & 0.009 \\
\hline
\end{tabular}

Note. $*, * *$, and, $* * *$ indicate significance at the $0.10,0.05$, and 0.01 levels, respectively.

A second result lies in the relative strength of the autocorrelation. In general the magnitude of autocorrelation is higher for Portfolios 6 and portfolio 1 respectively. The average autocorrelation (across the 18 years) in stock returns is found to be $3 \%, 1.4 \%, 0.9 \%$ among portfolios 1,2 and 3 stocks respectively. Among the sell pressure portfolio stocks, the average autocorrelations are $2.9 \%, 1.8 \%$, and $1.2 \%$ for portfolios 6,5 and 4 respectively. These results lend support to hypothesis 2 .

The results in Table 3 generally support the underlying assumption of persistence in buyer and seller initiated trades. The positive autocorrelations suggest that stocks that earned positive returns on day ( $\mathrm{t}-1)$ are also likely to earn positive return on day $(\mathrm{t})$, and vice versa for stocks that earned negative returns on day $(\mathrm{t}-1)$. Since the groupings of the stocks are based on the relative buy or sell pressures, the persistence in the performance from day (t-1) to day (t) might be indicative of persistence in buying and selling. In other words, on average, stocks that were among the most bought stocks on day (t-1) are more likely to have greater volume of buyer initiated trade on day $(t)$ than seller initiated trades. Similarly, the set of stocks that were heavily sold on day (t-1) are more likely to be sold than bought on day $(\mathrm{t})$.

\subsection{BUY and SELL Portfolio Returns}

Table IV presents the returns from buying the portfolios on day $(\mathrm{t})$ morning and selling them at market close on the same day. The portfolios are constructed using the fractional buy and sell volumes on day (t-1). All returns in 
Portfolio 1 (barring 2007 and 2008) are positive. Portfolios with relatively lower buy pressure (portfolio 2 and portfolio 3) have mixed positive and negative returns. In all but three years (2003, 2004, and 2006) the SELL portfolio (P6) earns a negative return. Interestingly on the sell side portfolios, P4 and P5 continue to demonstrate negative returns. These results suggest that the top $10 \%$ most bought stocks on day (t-1) are more likely to be purchased on day $(\mathrm{t})$. However, this trend dissipates fairly quickly as the buy pressure reduces. The day $(\mathrm{t})$ returns are found to be about $33.9 \%$ average per annum for portfolio 1 ; this reduces to $12.4 \%$ for portfolio 2 and $0 \%$ for portfolio 3 . The day $(\mathrm{t})$ returns are most negative for the $10 \%$ of the stocks, which were most heavily sold on day (t-1). Portfolio 6 earns an average return of about $-36 \%$ per annum. It reduces to $-35 \%$ per annum for portfolio 5 and $-31.7 \%$ for portfolio 4 . Thus, the selling effect seems to be more persistent in that, stocks that were heavily sold on day ( $\mathrm{t}-1)$ are more likely to be sold on day $(\mathrm{t})$. A possible explanation for this could be stronger sentiments in the market following selling than buying. Table IV, Panel B presents the alphas adjusted for the two Fama-French factors, the CAPM market factor, and the momentum factor (MOM). Portfolio 1 and portfolio 6 returns remain qualitatively unchanged.

Table 4. Panel A: raw daily return (in percentage)

\begin{tabular}{|c|c|c|c|c|c|c|}
\hline Year & $\mathrm{P} 1$ & $\mathrm{P} 2$ & P3 & P4 & P5 & P6 \\
\hline 1993 & 0.00308 & 0.00224 & 0.00191 & -0.00138 & -0.00147 & -0.0016 \\
\hline 1994 & 0.00246 & 0.00172 & 0.00121 & -0.00183 & -0.00198 & -0.0023 \\
\hline 1995 & 0.00336 & 0.00288 & 0.00238 & -0.00048 & -0.00098 & -0.0012 \\
\hline 1996 & 0.00301 & 0.00221 & 0.00153 & -0.00156 & -0.00169 & -0.00168 \\
\hline 1997 & 0.00247 & 0.00174 & 0.0009 & -0.00134 & -0.00141 & -0.00202 \\
\hline 1998 & 0.00096 & -0.00007 & -0.00077 & -0.00263 & -0.00296 & -0.00325 \\
\hline 1999 & 0.00115 & 0.00015 & -0.00067 & -0.00219 & -0.00239 & -0.00214 \\
\hline 2000 & 0.00033 & -0.00068 & -0.00222 & -0.00458 & -0.00457 & -0.00343 \\
\hline 2001 & 0.00204 & 0.00119 & 0.00028 & -0.00114 & -0.00132 & -0.00111 \\
\hline 2002 & 0.00167 & -0.0001 & -0.00077 & -0.00082 & -0.00054 & -0.00035 \\
\hline 2003 & 0.00305 & 0.00149 & 0.00122 & 0.00109 & 0.00118 & 0.00152 \\
\hline 2004 & 0.0017 & 0.00029 & -0.00026 & -0.00006 & -0.00004 & 0.00029 \\
\hline 2005 & 0.00067 & -0.00033 & -0.00075 & -0.00068 & -0.00066 & -0.00027 \\
\hline 2006 & 0.00083 & 0 & -0.00017 & 0.00014 & 0.00004 & 0.00009 \\
\hline 2007 & -0.00011 & -0.00103 & -0.00113 & -0.00071 & -0.00091 & -0.00083 \\
\hline 2008 & -0.00301 & -0.00303 & -0.0025 & -0.00315 & -0.00384 & -0.00506 \\
\hline 2009 & 0.00045 & -0.0001 & -0.00008 & -0.00075 & -0.00107 & -0.00169 \\
\hline 2010 & 0.00008 & 0.00002 & -0.00015 & -0.00064 & -0.00066 & -0.00097 \\
\hline Average & 0.00134 & 0.00048 & 0 & -0.00126 & -0.0014 & -0.00144 \\
\hline
\end{tabular}

Note. Table 4; Panel A reports the portfolio returns before adjusting for any risk factors. All of the portfolios have equal weights, and in each year, the portfolio returns are calculated by taking the simple average of daily portfolio returns.

Table 4. Panel B: average daily returns adjusted for market, size, book-to-market and momentum factors

\begin{tabular}{lcccccc}
\hline year & P1 & P2 & P3 & P4 & P5 & P6 \\
\hline Alpha & $0.00123 * * *$ & $0.00039 * * *$ & $-0.00009 * *$ & $-0.00132 *$ & $-0.00147 * *$ & $-0.00153 * *$ \\
\hline
\end{tabular}

Note. Table 4; Panel B reports the portfolio alphas after adjusting raw returns for market, size, book-to-market and then momentum factor. *, **, and, *** indicate significance at the $0.10,0.05$, and 0.01 levels, respectively.

Our naïve strategy involves taking a long position in portfolio 1 and a simultaneous short position in portfolio 6 at market open. We hold these positions till the end of the trading day and before the market closes, we reverse our positions and exit the market. Table $\mathrm{V}$ presents the results of this trading strategy, by year. The numbers represent the average daily return from holding the above long-short positions. The first column presents the raw unadjusted returns. Second column adjusts the returns for the CAPM market factor. Third column adds the two Fama-French factors (HML, SMB), and finally the fourth column brings in the MOM (momentum) factor. The daily returns range from $48 \mathrm{bp}$ to $42 \mathrm{bp}$ from 1993 to 1998. Post 1998 the returns decline steadily and the lowest returns are in 2006 and 2007 (about 7.3 bp per day). 
Table 5. Alphas for the long short portfolio

\begin{tabular}{lllcc}
\hline Year & Unadjusted & Market & Market, Size, BM & Market, Size, BM, and Momentum \\
\hline 1993 & 0.0047 & 0.0046 & 0.0045 & 0.0045 \\
& & $(25.66)$ & $(24.52)$ & $(24.53)$ \\
1995 & 0.0046 & 0.0044 & 0.0043 & 0.0043 \\
& & $(25.33)$ & $(24.94)$ & $(24.62)$ \\
1997 & 0.0045 & 0.0042 & 0.0043 & 0.0043 \\
& & $(24.55)$ & $(23.81)$ & $(23.79)$ \\
1999 & 0.0033 & 0.0031 & 0.0031 & 0.0031 \\
& & $(14.35)$ & $(14.17)$ & $(14.16)$ \\
2001 & 0.0031 & 0.003 & 0.003 & 0.003 \\
& & $(11.43)$ & $(11.29)$ & $(11.20)$ \\
2003 & 0.0015 & 0.0015 & 0.0016 & 0.0015 \\
& & $(8.55)$ & $(8.45)$ & $(8.24)$ \\
2005 & 0.0009 & 0.0008 & 0.0008 & 0.0008 \\
& & $(6.01)$ & $(5.96)$ & $(5.84)$ \\
2007 & 0.0007 & 0.0005 & 0.0005 & 0.0005 \\
& & $(3.86)$ & $(3.40)$ & $(3.44)$ \\
2009 & 0.0021 & 0.0021 & 0.0021 & 0.002 \\
& & $(6.89)$ & $(6.80)$ & $(6.43)$ \\
Average alpha & 0.0028 & 0.0027 & 0.0026 & 0.0026 \\
\hline
\end{tabular}

Note. This table reports the daily returns (in percentage) of a trading strategy that is long stocks with highest percentage of buyerinitiated trades and short stocks with the highest percentage of seller-initiated trades. BUY portfolio consists of portfolio P1 while the SELL portfolio consists of portfolio P6. Portfolio returns are equally weighted. The intercepts presented in this table are the strategy return, adjusted for various risk factors. For the sake of brevity we present numbers from alternate years. All alphas are significant at $1 \%$.

The positive return in 2007 might seem puzzling at first glance because all stock returns declined in that year; however, by taking a closer look at Table IV, Panel A reveals that in 2007, sell portfolio observed a greater decline (short position) than the buy portfolio (long position) thus leading to an overall positive return. Figure 1 presents the annualized, unadjusted returns of the above trading strategy. The average daily return from the long-short trading strategy is found to be about $27.89 \mathrm{bp}$. Adjusting for CAPM reduces it marginally to $26.57 \mathrm{bp}$. Additional risk adjustment using the Fama-French factors and the momentum factors do not make any significant difference.

Figure 2 presents the BUY-SELL returns by day of the week. For sake of clarity, we present only Monday and Friday returns in the figure. Monday returns are found to be consistently greater than Friday returns. A possible explanation for this may be found in Abraham and Ikenberry, (1994), and, Lakonishok, and Maberly (1990). According to them, Individual investors are likely to devote weekends for fundamental research and therefore, they are more likely to be active on Monday than on other weekdays. At the same time, institutional investors devote Monday morning to strategically planning the remaining week, thereby being less active traders than usual (Note 14).

Ariel (1987) reported a noticeable difference in mean returns for the nine-day period stretching from the last business day of a month to the eighth business day of the subsequent month as compared to returns measured over a nine-day period preceding the month-end. This effect was named "turn of the month effect" and has since become another of the widely researched and debated calendar anomalies in the financial market. Figure 3 compares the daily BUY-SELL portfolio returns by year, for the first 10 days of the month, vs. the last 10 days of the month. We find that in all the sample years, the strategy earned higher return during the first ten days of the month, compared to the last 10 days of the month. This result is consistent with the turn-of-the-month (TOM) effect whereby returns are found to be higher during the first few trading days of each month (see, for instance, McConnell \& Xu, 2008; Nikkinen et al., 2007). 


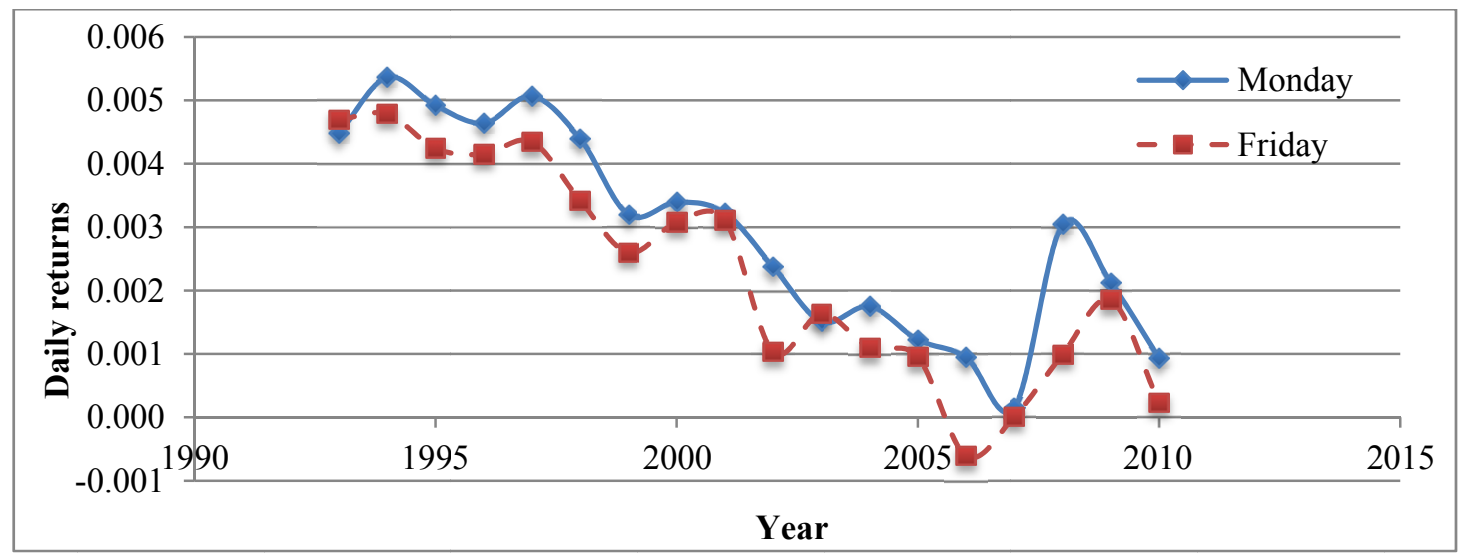

Figure 2. Day of the week effect

Note. This figure presents the equal-weighted average portfolio return differences between the "buy" portfolio (Portfolio 1) and the "sell" portfolio (Portfolio 6) on two days in a week (Monday and Friday) in each year before adjusting common risk factors from 1993 to 2010.

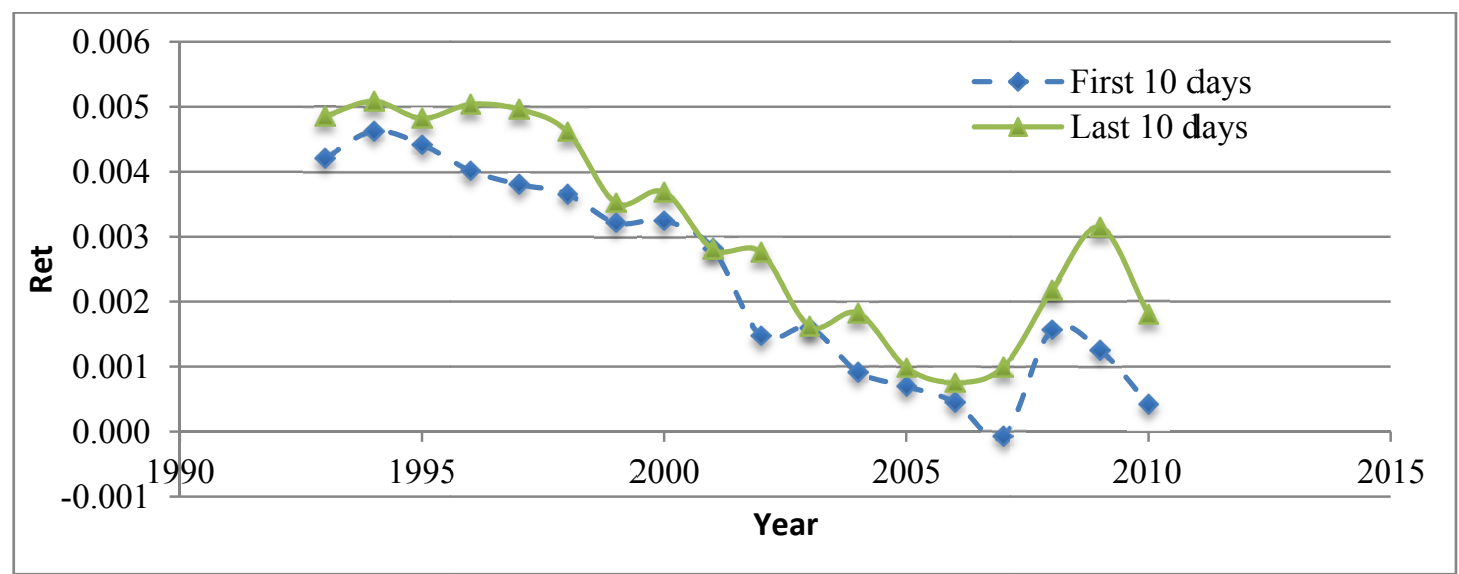

Figure 3. Beginning vs. end of the month

Note. This figure presents the equal-weighted average portfolio return differences between the "buy" portfolio (Portfolio 1) and the "sell" portfolio (Portfolio 6) in the first ten calendar days, in the last ten calendar days, and in the period between these two intervals before adjusting for common risk factors from 1993 to 2010 .

\subsection{Taking a Closer Look at the Returns}

Table 6. Correlations between equation 2 explanatory variables

\begin{tabular}{lcccccccc}
\hline & BMS & ln_CAP & PCT_down & RET_SP500 & DS & TS & In_VIX & SI \\
\hline BMS & 1 & & & & & & & \\
ln_CAP & $-0.30^{* * *}$ & 1 & & & & & & \\
PCT_down & $-0.29 * * *$ & $0.42^{* * *}$ & 1 & & & & & \\
RET_SP500 & $0.24^{* * *}$ & $-0.12^{* * *}$ & $-0.82^{* * *}$ & 1 & & & & \\
DS & $0.24^{* * *}$ & $0.06^{* * *}$ & $0.10^{* * *}$ & -0.02 & 1 & & & \\
TS & $-0.14^{* * *}$ & $-0.28^{* * *}$ & $-0.03^{* *}$ & -0.01 & $0.39^{* * *}$ & 1 & & \\
ln_VIX & $-0.16^{* * *}$ & $0.11^{* * *}$ & $0.64^{* * *}$ & $-0.73^{* * *}$ & -0.02 & -0.02 & 1 & \\
SI & $0.27^{* * *}$ & $0.22^{* * *}$ & $0.07^{* * *}$ & -0.02 & $-0.05^{* * *}$ & $-0.41^{* * *}$ & 0.02 & 1 \\
\hline
\end{tabular}

Note. This tables reports the correlation coefficient estimates relating: ln_CAP, which is the natural logarithm of the absolute value of stock's market capitalization. PCT_down, is the fraction of stocks in the market which earned a negative return from day (t-1) to day (t), RET_SP500 is the day (t) return on S\&P 500 index, $\ln \_$VIX is the return of volatility index, DS is the default spread and TS is the term spread, and SI is the month investor sentiment index. *, **, and *** indicate significance at the $0.10,0.05$, and 0.01 levels, respectively. 
The results thus far suggest that the BUY-SELL portfolio tends to earn a significant positive abnormal return even after adjusting for the CAPM, Fama-French and Momentum risk factors. In this section we use the specification laid out in equation (2) to get some understanding of the potential driver of the above-observed BUY SELL portfolio returns. Table 6 presents the Pearson correlation coefficients between BMS and the explanatory variables in equation (2).

Table 7 presents the results of Fama-Macbeth analysis using reduced and full form of equation (2). High correlations between PCT_down, Ret_SP500 and ln_VIX (Table 6) raises concerns of multicolliniarity affecting the results reported in this table. The results from various reduced forms of equation (2) are presented in Table VII as robustness. The results are consistent across the various models. Controlling for the market cap of the BUY minus SELL portfolio, we find the following results: BMS is positively related to the Baker and Wurgler's Investor sentiment index (SI) suggesting that the returns from the BUY-SELL portfolio is likely to be higher in periods of high sentiment. This can be a result of either strong persistence in BUY portfolio and/or strong persistence in SELL portfolio. PCT_down is estimated as the fraction of stocks whose price went down on the given day, vis-à-vis their closing prices on the previous day. A high value of this variable would denote a slump in the market. The negative coefficient on PCT down suggests that BMS returns are likely to be low during market downturns. This result is consistent with buyers being more aggressive in bull market and sellers being more aggressive in bear market (Note 15).

VIX measures the investor expectations regarding market volatility in the next 30 days as implied by the skewness of S\&P 500 index options, and has been dubbed the "Investor Fear Gauge" When the VIX is high (i.e. when implied volatility is high), investor sentiment is presumed to be low since investors are assumed to be risk averse. Therefore the negative correlation between these variables and BMS is consistent with the positive relation between BMS and SI. This result is consistent with Antoniou, Doukas, and Subrahmanyam (2013). They find robust evidence suggesting strong momentum in optimistic periods and virtually no momentum in pessimistic periods. The similarity suggests that sentiment might be affecting BMS portfolio in manners similar to the momentum portfolios.

Table 7. Explaining the BMS (buy minus sell) factor

\begin{tabular}{|c|c|c|c|c|c|c|c|c|}
\hline Intercept & ln_CAP & PCT_down & RET_SP500 & DS & TS & ln_VIX & SI & Average Adj. $\mathrm{R}^{2}$ \\
\hline 0.026 & & & & & & & 0.006 & 0.117 \\
\hline$(2.367)$ & & & & & & & (3.377) & \\
\hline 0.027 & & & & & & -0.031 & & 0.038 \\
\hline$(2.820)$ & & & & & & $(-1.327)$ & & \\
\hline 0.029 & & & & & -0.115 & & & 0.022 \\
\hline (2.489) & & & & & $(-1.045)$ & & & \\
\hline 0.019 & & & & 0.576 & & & & 0.084 \\
\hline$(2.905)$ & & & & $(2.276)$ & & & & \\
\hline 0.027 & & & 0.231 & & & & & 0.085 \\
\hline$(2.160)$ & & & $(4.361)$ & & & & & \\
\hline 0.036 & & -0.020 & & & & & & 0.095 \\
\hline$(2.202)$ & & $(-2.741)$ & & & & & & \\
\hline 0.100 & -0.004 & -0.007 & 0.164 & 0.920 & -0.229 & 0.011 & 0.005 & 0.401 \\
\hline$(2.360)$ & $(-2.643)$ & $(-2.014)$ & $(4.742)$ & (3.003) & $(-1.188)$ & $(1.777)$ & (1.417) & \\
\hline 0.101 & -0.004 & -0.006 & 0.142 & 0.916 & -0.231 & & 0.005 & 0.399 \\
\hline$(2.950)$ & $(-2.457)$ & $(-3.048)$ & (3.977) & $(3.842)$ & $(-1.196)$ & & $(2.485)$ & \\
\hline
\end{tabular}

Note. The dependent variable BMS is the Buy-minus-Sell variable. BUY portfolio consists of the set of portfolio 1 stocks, while SELL portfolio consists of the set of portfolio 6 stocks. The set of independent variables includes: ln_CAP, which is the natural logarithm of the absolute value of stock's market capitalization (calculated by using the average stocks' market capitalizations in the buy portfolio minus the average stock-sizes in the sell portfolio). PCT_down, is the fraction of stocks in the market which earned a negative return from day (t-1) to day (t), RET_SP500 is the day ( $\mathrm{t}$ ) return on S\&P 500 index, ln_VIX is the return of volatility index, DS is the default spread, TS is the term spread, and SI is the monthly investor sentiment index. The t-statistics are given in the parentheses. The far right column reports the average adjusted annual R-square, calculated across the sample period (18 years).

The coefficients on default spreads are significantly positive, while the coefficients on term spreads are significantly negative. To the extent that Default spreads are high during recession and low during expansion 
(Fama-French, 1988), this result suggests that, ceteris paribus, BMS returns are high during recessions. Chordia and Shivakumar (2002) find that momentum profits are only significant in periods in which the economy is expanding. This difference suggests that at least partially, BMS returns are different from the well-established momentum returns. The S\&P 500 coefficient is significantly positive suggesting that the BUY-SELL strategy earns higher return during market upturn. This result is consistent with the findings of Cooper, Gutierrez, and Hameed (2004). They suggest that momentum is profitable only after market increases.

Therefore, in conclusion, Table 7 analysis suggests that BMS returns are likely to be high in buyer driven market (PCT_Down), during periods of increased optimism (SI), less fear in the market (VIX) and during market upturn. Drawing from the extant momentum literature, these would suggest that BMS should be high during expansionary phase of the market. However, the positive coefficient on Default spreads suggests that, ceteris paribus, BMS is likely to be high during recessionary periods. While this result is seemingly puzzling, the high positive return observed in 2007 and 2008 (Tables 4, and 5) provides some clue to understanding it. During sharp downturn in the market, the selling portfolio loses much more than the buyer portfolio. Therefore the buy minus sell position ends up with a net positive during sharp recessions. One possible explanation for this could be drawn from Antoniou et al. (2013). The cognitive dissonance observed by them possibly affects net sold stock values much more than the net bought stocks, during market crashes (such as the one observed in 2007, 2008).

\section{The BMS Factor}

Table IV highlights the inability of the four-factor model to explain the BUY and SELL portfolio returns. A closer look at these returns in table 7 brings out the role of investor sentiment and economic stability (default and term spreads) in their formation. To the extent that these parameters could be at least partially systematic in nature, we conjecture that the BMS returns might be possibly picking a sentiment-related short-term asset-pricing factor, which is not accounted for by either the CAPM market factor, or, the Fama-French SMB and HML factors, or the Carhart Momentum factor. This section briefly explores this aspect of the (BUY-SELL) return.

We examine how the BMS return factor performs vis-à-vis the Capital Asset Pricing Model (CAPM), Fama-French (1993) model, and, Carhart (1997) model by comparing the model $\mathrm{R}^{2}$ from equation (3) and its various reduced forms.

$$
R_{i t}-R_{r t}=\alpha_{i T}+m_{i T} B M S_{t}+b_{i T} R M R F_{t}+s_{i T} S M B_{t}+h_{i T} H M L_{t}+u_{i T} U M D_{t}+\varepsilon_{i t}
$$

We estimate each model specification for each stock in each year. The model $\mathrm{R}^{2}$ in a given year is estimated as the cross-sectional average of adjusted R-squares from the stock level regressions in that year. This provides an intuitive measure that expresses the fraction of the average excess returns captured by the model. Table 8 presents the results. Here we make three sets of comparisons: first, the adjusted $\mathrm{R}^{2}$ of Model 1 (CAPM) with Model 2 (CAPM augmented with BMS); second, Model 3 (Fama-French 3-factor model) and Model 4 is (Model 3 with the BMS factor); and third, Model 5 (Carhart 4-factor model) and Model 6 (Model 5 the BMS). The adjusted $\mathrm{R}^{2}$ show a consistent increase across each comparison, the magnitude of the increase remains fairly stable through the years. The BMS improves the explanatory power of models 1 (CAPM), 3 (3-factor), and 5 (4-factor) by an average $0.7 \%, 0.58 \%$, and $0.53 \%$ per annum, respectively. The BMS factor is most significant during 2007 (1.19\%, 0.97\%, and 0.89\% improvement over CAPM, 3-factor and 4-factor models respectively), followed by 2008 .

Reading the results of Table 8 along with those presented in Tables V and VII seems to point at the role of investor sentiments in explaining the above patterns. During normal times, the pessimism driving the net sold portfolios closely balances the optimism driving the net bought portfolio. During bull (bear) markets, optimism (pessimism) dominates over pessimism (optimism) thus making the long (short) portion of BMS more relevant. Our results seem to suggest that during market crashes the pessimistic sentiment is much stronger towards the set of most sold stocks. Thus, in 2007 and 2008 when almost all stocks were being sold (negative returns on all portfolios in Table IV), the negative sentiment affecting P6 (the set of most sold stocks) was much stronger than the sentiments driving P1 (the set of least sold stocks). 
Table 8. Examination of BMS loadings

\begin{tabular}{|c|c|c|c|c|c|c|}
\hline Year & $\begin{array}{l}\text { Model1 } \\
\text { RMRF }\end{array}$ & $\begin{array}{c}\text { Model2 } \\
\text { RMRF, BMS }\end{array}$ & $\begin{array}{c}\text { Model3 } \\
\text { SMB,HML, } \\
\text { RMRF }\end{array}$ & $\begin{array}{c}\text { Model4 } \\
\text { SMB,HML, } \\
\text { RMRF,BMS }\end{array}$ & $\begin{array}{c}\text { Model5 } \\
\text { SMB,HML, } \\
\text { RMRF,UMD }\end{array}$ & $\begin{array}{c}\text { Model6 } \\
\text { SMB,HML, } \\
\text { RMRF,UMD, BMS }\end{array}$ \\
\hline 1993 & 0.0284 & 0.0359 & 0.0534 & 0.0594 & 0.0610 & 0.0663 \\
\hline 1994 & 0.0414 & 0.0472 & 0.0628 & 0.0681 & 0.0689 & 0.0738 \\
\hline 1995 & 0.0292 & 0.0364 & 0.0527 & 0.0580 & 0.0589 & 0.0631 \\
\hline 1996 & 0.0419 & 0.0486 & 0.0696 & 0.0752 & 0.0767 & 0.0818 \\
\hline 1997 & 0.0590 & 0.0657 & 0.0869 & 0.0924 & 0.0930 & 0.0984 \\
\hline 1998 & 0.0810 & 0.0865 & 0.1137 & 0.1186 & 0.1215 & 0.1256 \\
\hline 1999 & 0.0335 & 0.0413 & 0.0617 & 0.0678 & 0.0688 & 0.0747 \\
\hline 2000 & 0.0668 & 0.0741 & 0.1015 & 0.1072 & 0.1104 & 0.1161 \\
\hline 2001 & 0.0899 & 0.0973 & 0.1243 & 0.1308 & 0.1380 & 0.1442 \\
\hline 2002 & 0.1215 & 0.1276 & 0.1498 & 0.1556 & 0.1638 & 0.1689 \\
\hline 2003 & 0.1143 & 0.1197 & 0.1418 & 0.1464 & 0.1489 & 0.1524 \\
\hline 2004 & 0.1220 & 0.1283 & 0.1534 & 0.1588 & 0.1600 & 0.1658 \\
\hline 2005 & 0.1225 & 0.1282 & 0.1519 & 0.1572 & 0.1606 & 0.1659 \\
\hline 2006 & 0.1462 & 0.1540 & 0.1739 & 0.1805 & 0.1851 & 0.1902 \\
\hline 2007 & 0.1993 & 0.2112 & 0.2281 & 0.2378 & 0.2426 & 0.2515 \\
\hline 2008 & 0.2987 & 0.3082 & 0.3387 & 0.3460 & 0.3482 & 0.3554 \\
\hline 2009 & 0.2946 & 0.2991 & 0.3195 & 0.3230 & 0.3291 & 0.3328 \\
\hline 2010 & 0.3029 & 0.3088 & 0.3288 & 0.3337 & 0.3372 & 0.3418 \\
\hline
\end{tabular}

Note. This table presents the average R-squares from year 1993 to 2010 by regressing the stock returns on different risk factors. The daily BMS factor is formed by taking the daily return difference between the "BUY" portfolio, which includes stocks with the top $10 \%$ of buyer-initiated trades and the "SELL" portfolio, which includes stocks with the top $10 \%$ of seller-initiated trades. BMS is the difference between the returns on the BUY and the SELL portfolios.

\section{Conclusion}

We start this study with a conjecture that in the short run, buying and selling pressures are likely to be persistent. We attempt to find evidence in support of this conjecture by devising a three-step naïve trading strategy. Step 1: We observe all buying and selling across all stocks in the market on day ( $\mathrm{t}$ ). We eliminate $20 \%$ of the least liquid stocks from the population and rank the remaining $80 \%$ into deciles based on the fraction of buyer initiated trade to total trade. We designate the decile with the $10 \%$ most heavily bought stocks as BUY portfolio and the decile with $10 \%$ most heavily sold stock as SELL portfolio. Step 2: On day $(\mathrm{t}+1)$, at market open, we take a long position in the BUY portfolio and a simultaneous short position in the SELL portfolio. Step 3: we reverse our positions at market close on day $(\mathrm{t}+1)$, and exit the market. We find that this strategy earned an average return of about 47 basis points per day in 1993, decreased to 7.3 basis points per day in 2006 and 2007. Since then the returns increased to $20.5 \mathrm{bp}$ in 2008 and 2009 and $10 \mathrm{bp}$ in 2010.

The strategy returns are robust to CAPM, Fama-French and Momentum factor risk adjustment. The returns are positively related to investor sentiment in the market as well as to economic stability measures such as term spread and default spread. At least some of the returns seem to be related to market cap, with large cap stocks contributing to the BUY portfolio and the small cap stocks contributing to SELL portfolio. The results suggest that during expansionary phase in the market, the trading in large cap stocks are more likely to be buyer initiated, while in recessionary periods, the trading in small stocks are more likely to be seller initiated. Our results suggest that order-imbalance displayed strong positive autocorrelation till 1998. Post 1998, the autocorrelation and the resulting return momentum has been declining. Anecdotal evidences as well as trends observed in other studies such as Hendershott, Jones and Menkveld (2011) suggest that the rise in algorithmic trading might be responsible for the post 1998 weakening and more recent near disappearance of this seeming weak form market inefficiency.

\section{References}

Abraham, A., \& Ikenberry, D. L. (1994). The individual investor and the weekend effect. Journal of Financial and Quantitative Analysis, 29, 263-277. http://dx.doi.org/10.2307/2331225

Anderson, R. M. (2011). Time-varying risk premia. Journal of Mathematical Economics, 47, $253-259$. 
http://dx.doi.org/10.1016/j.jmateco.2010.12.010

Antoniou, C., Doukas, J. A., \& Subrahmanyam, A. (2013). Cognitive dissonance, sentiment and momentum. Journal of Financial and Quantitative Analysis, 48, 245-275. http://dx.doi.org/10.1017/S0022109012000592

Ariel, R. A. (1987). Monthly Effects in Stock Returns. Journal of Financial Economics, 18, 161-174. http://dx.doi.org/10.1016/0304-405X(87)90066-3

Atchison, M. D., Butler, K. C., \& Simonds, R. R. (1987). Nonsynchronous Security Trading and Market Index Autocorrelation. The Journal of Finance, 42(1), 111-118. http://dx.doi.org/10.1111/j.1540-6261.1987.tb02553.x

Baker, M., \& Wurgler, J. (2007). Investor sentiment and the stock market. Journal of Economic Perspectives, 21, 129-151. http://dx.doi.org/10.1257/jep.21.2.129

Bernhardt, D., \& Davies, R. J. (2008). The Impact of Nonsynchronous Trading on Differences in Portfolio Cross-Autocorrelations. Retrieved from http://ssrn.com/abstract=981084

Brogaard, J., Hendershott, T., \& Riordan, R. (2013). High Frequency Trading and Price Discovery. Retrieved from http://ssrn.com/abstract $=1928510$

Carhart, M. M. (1997). On persistence in mutual fund performance. The Journal of Finance, 52(1), 57-82. http://dx.doi.org/10.1111/j.1540-6261.1997.tb03808.x

Chordia, T., \& L. Shivakumar. (2002). Momentum, Business Cycle, and Time-Varying Expected Returns. Journal of Finance, 57, 985-1019. http://dx.doi.org/10.1111/1540-6261.00449

Chordia, T., \& Subrahmanyam, A. (2004). Order imbalance and individual stock returns: Theory and evidence. Journal of Financial Economics, 72, 485-518. http://dx.doi.org/10.1016/S0304-405X(03)00175-2

Chordia, T., Roll, R., \& Subrahmanyam, A. (2001). Market Liquidity and Trading Activity. The Journal of Finance, 56(2), 501-530. http://dx.doi.org/10.1111/0022-1082.00335

Chordia, T., Roll, R., \& Subrahmanyam, A. (2002). Order Imbalance, Liquidity, and Market Returns. Journal of Financial Economics, 65(1), 111-130. http://dx.doi.org/10.1016/S0304-405X(02)00136-8

Cooper, M. J., Gutierrez Jr., R. C., \& Hameed, A. (2004). Market States and Momentum. Journal of Finance, 59, 1345-1365. http://dx.doi.org/10.1111/j.1540-6261.2004.00665.x

De Long, J. B., Shleifer, A., Summers, L., \& Waldmann, R. (1990a). Noise trader risk in financial markets. Journal of Political Economy, 98(4), 703-738. http://dx.doi.org/10.1086/261703

Fama, E. F., \& French, K. R. (1988). Permanent and Temporary Components of Stock Prices. Journal of Politiccal Economy, 96(2), 246-273. http://dx.doi.org/10.1086/261535

Fama, E. F., \& French, K. R. (1993). Common Risk Factors in the Returns on Stocks and Bonds. The Journal of Financial Economics, 33(1), 3-56. http://dx.doi.org/10.1016/0304-405X(93)90023-5

Jegadeesh, N., \& Sheridan, T. (1993). Returns to buying winners and selling losers: Implications for stock market efficiency. Journal of Finance, 48, 65-91. http://dx.doi.org/10.1111/j.1540-6261.1993.tb04702.x

Kumar, A., \& Lee, C. M. C. (2006). Retail investor sentiment and return comovements. Journal of Finance, 61(5), 2451-2486. http://dx.doi.org/10.1111/j.1540-6261.2006.01063.x

Lakonishok, J., \& Maberly, E. (1990). The weekend effect: trading patterns of individual and institutional investors. Journal of Finance, 45, 231-241. http://dx.doi.org/10.1111/j.1540-6261.1990.tb05089.x

Lee, C. M. C., \& Radhakrishna, B. (2000). Inferring Investor Behaviour: Evidence from TORQ Data. Journal of Financial Markets, 3(2), 83-111. http://dx.doi.org/10.1016/S1386-4181(00)00002-1

Lee, C. M. C., \& Ready, M. J. (1991). Inferring Trade Direction from Intraday Data. Journal of Finance, 46(2), 733-746. http://dx.doi.org/10.1111/j.1540-6261.1991.tb02683.x

Lee, W. Y., Jiang, C. X., \& Indro, D. C. (2002). Stock Market Volatility, Excess Returns, and the Role of Investor Sentiment. Journal of Banking and Finance, 26(12), 2277-2299. http://dx.doi.org/10.1016/S0378-4266(01)00202-3

Lintner, J. (1965). The valuation of risk assets and selection of risky investments in stock portfolios and capital budgets. Review of Economics and Statistics, 47, 13-37. http://dx.doi.org/10.2307/1924119

Lo, A. W., \& MacKinlay, A. C. (1988). Stock Market Prices do not Follow Random Walks: Evidence from a 
Simple Specification Test. Review of Financial Studies, 1(1), 41-66. http://dx.doi.org/10.1093/rfs/1.1.41

McConnell, J. J., \& Xu, W. (2008). Equity returns at the turn of the month. Financial Analysts Journal, 64, 4964. http://dx.doi.org/10.2469/faj.v64.n2.11

Nikkinen, J., Sahlstrom, P., \& Aijo, J. (2007). Turn-of-the-month and intraday effects: explanation from the important macroeconomic news announcements. The Journal of Futures Market, 27, 105-126. http://dx.doi.org/10.1002/fut.20244

Odders-White, E. R. (2000). On the Occurrence and Consequences of Inaccurate Trade Classification. Journal of Financial Markets, 3(3), 259-286. http://dx.doi.org/10.1016/S1386-4181(00)00006-9

Sharpe, W. F. (1964). Capital Asset Pries: A theory of Market Equilibrium under Conditions of Risk. Journal of Finance, 19(3), 425-442.

\section{Notes}

Note 1. Hereafter we will refer to the Jegadeesh and Titman (1993) momentum as JTM.

Note 2. Figure 1 of Hendershott, Jones and Menkveld (2011) suggests that algorithmic trading increased steeply from beginning of 2001 through the end of 2006. If we assume that the growth of algorithmic trading on the NYSE would be representative of the growth across all the markets, we can compare the trends observed by them with the trends in the returns earned by the BUY minus SELL portfolio. The monthly correlation between these two series is -0.92 . Brogaard, Hendershott, and Riordan (2013) find that HFT trades are positively correlated with permanent price changes and negatively correlated with transitory price changes, suggesting that HFT reduces short term potential mispricing.

Note 3. We drop all trades with non-standard settlement conditions (excluded all trades with a correction indicator other than 0 or 1 , and retain only those trades for which the condition is $\mathrm{B}, \mathrm{J}, \mathrm{K}$, or $\mathrm{S}$ ). We also drop all trades with non-positive trade size or price. Finally, we omit all trades recorded before opening time or after the closing time of the market. Negative bid-ask spreads and transaction prices are also eliminated. We eliminate all quotes for which the quoted spread is greater than $20 \%$ of the quote midpoint, when the quote midpoint is greater than $\$ 10$ or when the quoted spread is greater than $\$ 2$, when the quote midpoint is less than $\$ 10$.

Note 4 . We eliminate all quotes for which either the ask or the bid moves by more than $50 \%$. All quotes with condition $5,7,8,9,11,13,14,15,16,17,19,20,27,28,29$ were excluded.

Note 5. http://mba.tuck.dartmouth.edu/pages/faculty/ken.french/data_library.html

Note 6. http://people.stern.nyu.edu/jwurgler/

Note 7. As robustness, we classify all the trades into buyer or seller initiated using only the tick-test and dropping all trades, which could not be classified. It does not qualitatively affect the results.

Note 8. As test of robustness, we construct portfolios using fractional buyer initiated trading volume instead of the fractional number of buyer-initiated trade. The results remain qualitatively similar. For sake of brevity, we present only results obtained using the fractional number of buy trade decile portfolios.

Note 9. The choice of AR(1) model is driven by the data whereby we checked for existence of up to 10 lag correlation, and found AR(1)should be the best fit.

Note 10. Market value weighted portfolios produce qualitatively similar results. For the sake of brevity we report only the analysis based on equally weighted portfolios.

Note 11. "Market" is the market factor (the value-weighted index minus the risk-free rate). "SMB" is the size factor (small stocks minus big stocks), and "HML" is the book-to-market factor (high minus low book-to-market stocks). MOM is the momentum factor (winners minus losers).

Note 12. Since returns based on trade prices are likely to be affected by concerns of bid-ask bounce, we also estimate autocorrelations based on quote mid-point returns. The numbers remain qualitatively similar and therefore we believe that our results are not driven by bid-ask bounces. For sake of brevity, we present only the transaction price based results in the paper.

Note 13. Most studies of autocorrelation in individual stock returns have focused on the average autocorrelation of groups of firms, finding it to be usually statistically insignificant. For example see Safvenblad (2000).

Note 14. Although this is one plausible explanation, a caveat is in order here. Retail investors make up a progressively lower part of overall trading volume in equities internationally; hence, this effect may not 
necessarily be retail-motivated alone.

Note 15. BULL (BEAR) refers to an upward (downward) market.

\section{Copyrights}

Copyright for this article is retained by the author(s), with first publication rights granted to the journal.

This is an open-access article distributed under the terms and conditions of the Creative Commons Attribution license (http://creativecommons.org/licenses/by/3.0/). 